\title{
INFLUÊNCIA DO EPTC NO DESENVOLVIMENTO E ABSORCÃO DE MACRONUTRIENTES PELA CULTƯRA DE FEIJÃO (Phaseolus vulgaris L. VAR. CARIOCA)
}

\section{R. DEUBER*, P.N. CAMARGO** e R. FORSTER*}

* Pesquisadores Científicos. Instituto Agronômico - CP 28, 13.100 - Campinas (SP).

** Professor Adjunto. Escola Superior de Agricultura "Luiz de Queiroz", CP 9, 13.400 - Piracicaba (SP).

Parte da dissertação do primeiro autor para obtenção do grau de Mestre.

Recebido para publicação em 20.06.79.

\section{RESUMO}

O efeito de EPTC (S-etildipropiltiolcarbamato) sobre o desenvolvimento e a absorção de macronutrientes até o florescimento e os seus tecres nas sementes e vagens, na colheita, foi estudado em dois experimentos de campo com a cultura do feijão, var. Carioca.

$O$ EPTC foi aplicado em pré-plantio com incorporação nas doses de $0,1,2,4,8$ e $16 \mathrm{~kg} / \mathrm{ha}$ em dois experimentos em solos argiloso e barrento.

A avaliação da ação do herbicida sobre o desenvolvimento da cultura se fez pela obtenção de pesos de matéria seca de folhas, caules e vagens, durante o ciclo e número de plantas e produção de sementes na colheita.

No início do florescimento foram analisados os teores de N, P, K, Ca, Mg e S em folhas e caules $\mathrm{e}$, na colheita, em vagens e sementes.

$O$ EPTC, nas doses de 1,2 ou $4 \mathrm{~kg} /$ ha não afetou o desenvolvimento da cultura, não alterou o teor de nutrientes em folhas ou caules, no início do florescimento, nem o teor nos grãos ou vagens, na colheita. Também não alterou a população de plantas ou a produção de grãos.

As doses de 8 e $16 \mathrm{~kg} /$ ha de EPTC causaram redução de crescimento, de absorção de nutrien tes, número de plantas por área e produção de sementes. O ciclo da cultura foi alongado. Os teores de nutrientes foram mais elevados, em geral, nas folhas, caules e vagens. Com essas doses ocorreu maior acúmulo de $\mathrm{K}$ nas vagens na colheita.

Nenhuma das doses de EPTC, em qualquer dos experimentos, causou alteração nos teores de macronutrientes nas sementes.

UNITERMOS: EPTC, Feijão, Crescimento, Nutrição Mineral.

\section{SUMMARY}

INFLUENCE OF EPTC ON GROWTH AND MINERAL NUTRITION OF Phaseolus vulgaris CV. CARIOCA.

The effect of EPTC, on growth and the macronutrient content in leaves and stems, at flo- wering set, and in seeds and pods, at harvest, in common beans CV. Carioca was studied.

The EPTC was applied pre-plant incorporated at the dosages of $0,1,2,4,8$ and $16 \mathrm{~kg} / \mathrm{ha}$ in two experiments on clay and loamy soils.

The influence of the herbicide on the crop growth was evaluated by means of fresh and dry matter weights of leaves, stems and pods at diffe rent periods of the crop cycle and by the stand and seed production. In both experiments the concentration of $\mathrm{N}, \mathrm{P}, \mathrm{K}$. $\mathrm{Ca}, \mathrm{Mg}$ and $\mathrm{S}$ were ana lysed in leaves and stems at the flowering set. The content of the same nutrients in seeds and pods were determined at harvest.

Rates of 1,2 or $4 \mathrm{~kg} /$ ha of EPTC did not affect the crop growth or the nutrient content in leaves, stems, seeds or pods. Rates of 8 and 16 $\mathrm{kg} /$ ha reduced the plant growth, nutrient absorption, stand and yield, but the nutrient concentration was enhanced in leaves, stems and pods. With these rates of EPTC the $\mathrm{K}$ content in pods was signifficantly higher.

None of the applied rates of EPTC caused changes in the macronutrients concentration in

KEYWORDS: EPTC, Phaseolus vulgaris, Growth, Mineral Nutrition.

\section{INTRODUÇÃO}

O feijão comum, Phaseolus vulgaris L. é um alimento de grande importância no Brasil, mas, mesmo as sim, não tem recebido dos agricultores a devida atenção. De um modo geral tem sido cultivado em pequenas áreas ou intercalado em outras culturas.

A pesquisa, entretanto, já está bem adiantada no que diz respeito a the seeds at harvest. 
melhoramento genético e tratos culturais, sendo possivel conduzir a cultura do feijão extensivamente e com alta produtividade (1). Em algumas regiões do Brasil já se veem culturas extensas de feijão solteiro conduzidas segundo as técnicas mais avançadas. Nesses casos, torna-se obrigatória a mecanização e o controle do mato por outros meios que não o manual, uma vez que a mão-deobra se torna cada vez mais escassa e onerosa. A opção que se apresenta, então, é a do uso de herbicidas, que no caso do feijão são aplicados normalmente em pré-plantio com incorporação ou à superficie, após a semeadura e antes da emergência do mato (11).

Dentre os herbicidas seletivos à cultura do feijão está o EPTC, como evidenciam muitos trabalhos de pesquisa $(2,7,11,12,16,30)$, podendo mesmo ser aplicado em doses muito elevadas sem grandes danos (12).

Podem ocorrer, algumas vezes, al terações metabólicas e fisiológicas em plantas tratadas, inclusive variações na absorção de nutrientes. Assim, o EPTC causou alterações nos teores de vários nutrientes em plantas de Cyperus esculentus, trigo e milho (18), reduziu o metabolismo do nitrogênio em plantas de algodão (23) e causou decréscimo de teores de ácidos graxos na cutícula de folhas de Cassia obtusifolia (32). Em outros casos não ocorreram alterações de teores de nutrientes $(13,34)$.

Concentrações subletais de herbicidas também podem causar estímulo de crescimento de plantas como foi demonstrado por Wiedmann \& Appleby (31) aplicando dezesseis diferentes herbicidas em plantas de aveia.

Tendo em vista a perspectiva de grande utilização de herbicidas na cul tura do feijão é importante se conhecer perfeitamente seu modo de ação nas plantas cultivadas e os possiveis efeitos que possam causar na nutrição das plantas.

O objetivo do presente trabalho foi verificar se o EPTC, aplicado em diferentes doses, tem influência sobre o des envolvimento e absorção de nutrientes pelo feijão e se altera a composição das sementes no que diz respeito aos mesmos nutrientes.

\section{MATERIAL E MÉTODOS}

Foram instalados dois experimentos de campo no Centro Experimental de Campinas com a cultura do feijão (Phaseolus vulgaris L. Var. Carioca).

Experimento 1, de 1973-74.

Foi instalado em um latossolo roxo, série Chapadão (26), de textura argilosa, levemente ondulado e altitude média de $660 \mathrm{~m}$, apresentando, nos horizontes Alp e A., (0 a $20 \mathrm{~cm}$ ), as características físicas e químicas constantes no quadro 1 .

Aplicou-se o herbicida EPTC, nas doses de 0, $1,2,4,8$ e $16 \mathrm{~kg} / \mathrm{ha}$ em pré-plantio com incorporação ao solo à profundidade de $0,10 \mathrm{~m}$, com grade dupla de discos.

$\mathrm{O}$ delineamento experimental foi o de blocos ao acaso com cinco repeticões. As parcelas mediam 2,50m de largura por $\overline{6}, 00 \mathrm{~m}$ de comprimento e estavam afastadas $1,0 \mathrm{~m}$ entre si. Em cada parcela foram semeadas três sementes de feijão a cada $0,20 \mathrm{~m}$, em sulcos espaçados de $0,50 \mathrm{~m}$, com adubação prévia no sulco com uma mistura contendo $80 \mathrm{~kg}$ de P205, e $30 \mathrm{~kg}$ de $\mathrm{K} 20$ por hectare. O nitrogênio foi aplicado aos 25 dias após a emergênc;a da cultura na proporção de $20 \mathrm{~kg} / \mathrm{ha}$.

A aplicacão do EPTC foi feita no dia 8 de novembro de 1973, entre 9,00 e 10,00 horas, após perfeito preparo do solo, utilizando-se um pulverizador de gas carbónico de pressão constante de $2,81 \mathrm{~kg} / \mathrm{cm}$ e gastando 400 litros de água por hectare. A umidade do solo, nos primeiros $0,10 \mathrm{~m}$ se apresentava com $12,80 \%$ e a temperatura ambiente era de $25^{\circ} \mathrm{C}$ à sombra. $\mathrm{O}$ céu se apresentava sem nuvens e havia vento leve. Imediatamente após a aplicação fez-se a incorporação do herbicida.

A adubação e a semeadura foram feitas no dia 14 do mesmo mês. Vinte dias após fez-se a raleação das plantas ficando apenas duas a cada $0,20 \mathrm{~m}$.

Das seis linhas de cada parcela, as duas externas foram consideradas bordaduras, uma interna utilizada para amostragens de plantas para análise de crescimento e quimica, e três destinadas à avaliação da produção final de grãos.

$\mathrm{O}$ experimento foi mantido livre de mato por meio de dois cultivos com enxada, aos 26 e 42 dias após a semeadura. Plantas nascidas após a segunda capina foram eliminadas manualmente.

Aos 25 dias após a semeadura foram coletadas dez plantas de feijão por parcela para obtenção de pesos de matéria fresca e seca de folhas e caules. As plantas foram cortadas rente ao solo separando-se folhas e caules, pesando-se imediatamente o material, que, após, foi levado à secagem a $65^{\circ} \mathrm{C} \mathrm{em}$ secador de circulação forçada de ar para nova pesagem. O mesmo se fez aos 42 dias, sendo que as folhas, após a pesagem do material fresco, lavadas com água corrente, detergente e enxaguadas com água destilada e então levadas ao secador. Esse material foi submetido à análise química de teores de N, P, K, Ca, Mg e S. $\mathrm{O} \mathrm{N}$ e o $\mathrm{P}$ analisados pelos métodos estabelecidos por Lott et al. (24), o K por fotometria de chama de absorção (28), o Ca e Mg pela mesma técnica (6) e o S por espectrofotometria de absorção atômica (5).

Aos sessenta e três dias, fez-se nova amostragem de dez plantas para verificar os pesos de folhas, caules e vagens com sementes, proceden- 
Quadro 1 - Caracteristicas físicas e quimicas dos solos em que instalaram os experimentos com EPTC em cultura de feijão.

\begin{tabular}{lccc}
\hline CARACTERISTICAS & UNIDADES & EXPERIMENTO 1 & EXPERIMENTO 2 \\
\hline Teor de argila & $(<0,002 \mathrm{~mm})$ & $45,80 \%$ & $28,10 \%$ \\
Teor de limo & $(0,002 \mathrm{a} 0,02 \mathrm{~mm})$ & $19,60 \%$ & $6,80 \%$ \\
Teor de areia fina & $(0,02$ a $0,2 \mathrm{~mm})$ & $18,80 \%$ & $25,90 \%$ \\
Teor de areia grossa & $(0,2$ a $2,0 \mathrm{~mm})$ & $15,80 \%$ & $39,10 \%$ \\
pH & - & 6,00 & 5,70 \\
Teor de C & - & $2,80 \%$ & 1,51 \\
Teor de $\mathrm{PO}_{4}^{-3}$ & $($ e.mg/100 ml TFSA) & 0,02 & 0,19 \\
Teor de $\mathrm{K}^{+1}$ & $($ e.mg/100 ml TFSA) & 0,27 & 0,30 \\
Teor de Ca $+2+\mathrm{Mg}^{+2}$ & $($ e.mg/100 ml TFSA) & 2,95 & 3,80 \\
Classificação textural & - & argiloso & barrento \\
\hline
\end{tabular}

do-se da mesma forma que na primeira amostragem.

A colheita foi realizada no dia 5 de fevereiro de 1974, com um ciclo de 83 dias. Os grãos foram pesados e foi feita a separação daqueles que apresentavam defeitos ou má formação. Foram retira das dez plantas por parcela para análise do teor de macronutrientes nas vagens e sementes separadamente. Os pesos de matéria seca de caules e vagens de dez plantas também foram obtidos.

Experimento 2, de 1974-75.

Foi instalado, em um latossolo vermelho-escuro orto, série Barão (26), de textura barrenta, levemente ondulado, com altitude média de $680 \mathrm{~m}$, apresentando, nos horizontes Alp e A2 1 (0 a $20 \mathrm{~cm})$, as características fisicas e químicas constantes no quadro 1.

Os tratamentos e o delineamento foram os mesmos do Experimento 1.

A aplicacão do herbicida se fez no dia 24 de outubro de 1974 , entre as 8,00 e 9,00 horas, após perfeito preparo do solo que se apresentava limpo e sem torrões. Imediatamente após foi feita a incorporação do herbicida, com grade dupla de discos, à profundidade de $0,10 \mathrm{~m}$. A umidade do solo, nessa camada era de $7,20 \%$. A temperatura ambiente, à sombra era de $26^{\circ} \mathrm{C}$. O céu se apresentava sem nuvens e havia vento leve.

A aplicação do herbicida foi feita da mesma maneira que no experimento anterior, assim como a adubação e semeadura. Estas foram realizadas no dia 25 de outubro. A raleação de plantas se fez 20 dias após a semeadura. Esse experimento também recebeu dois cultivos aos 20 e 46 dias após a semeadura, para ficar livre de mato.

Aos 32 dias após a semeadura foi feita a primeira amostragem de plantas de feijão para verificação de pesos de matéria fresca e seca de folhas e caules, com 10 plantas por parcela. O procedimento foi o mesmo ao já descrito.

Aos 45 dias, fez-se nova amostragem para obtenção de pesos e para análise de teores de macronutrientes, procedendo-se como já descrito para o experimento anterior.

Aos 60 dias, foi realizada nova amostragem para obtenção de pesos de caules, folhas e vagens.

A colheita foi feita no dia 20 de janeiro de 1975, com um ciclo de 87 dias. Os mesmos dados obtidos no Experimento 1 foram também obtidos nesse, com excessão da porcentagem de grãos com defeito.

Todos os resultados dos dois experimentos, exceto os pesos de matéria fresca, foram submetidos à análíse estatística.

\section{RESULTADOS E DISCUSSÃO}

Desenvolvimento da cultura - Os resultados de pesos de matéria seca de folhas, caules e vagens de plantas dos Experimentos 1 e 2 estão nos quadros 2 e 3 , respectivamente. O EPTC foi bas tante fitotóxico na dose de $16 \mathrm{~kg} / \mathrm{ha}$ e, em menor grau, na de $8 \mathrm{~kg} / \mathrm{ha}$, no início do desenvolvimento do feijão. No Experimento 1, os pesos de folhas e caules mostram que a partir de 42 dias já se verificava recuperação das plantas e aos 63 dias essa recuperação parecia plena. No Experimento 2 as plantas apresentavam crescimento mais vigoroso, mas com igual dano pelo EPTC. Os efeitos fitotóxicos persistiam até os 45 dias como se pode verificar pelos pesos de folhas e caules. Aos 70 dias, houve plena recuperação aparentemente e pelos pesos que eram mesmo mais elevados com as do ses de 8 a $16 \mathrm{~kg}$ de EPTC. Isso se expli ca pelo fato de ter havido atraso no ciclo, pois as plantas, nesses tratamentos apresentavam maior número de folhas. $\mathrm{O}$ peso de vagens com sementes, no Experimento 1, aos 63 dias evidencia esse 
Quadro 2 - Pesos de maté ria seca de folhas, caules e vagens com sementes, por parcela, em cada época de amostragem do Experimento 1, em solo argiloso. Média de cinco repetições e amostra gem de dez plantas por parcela.

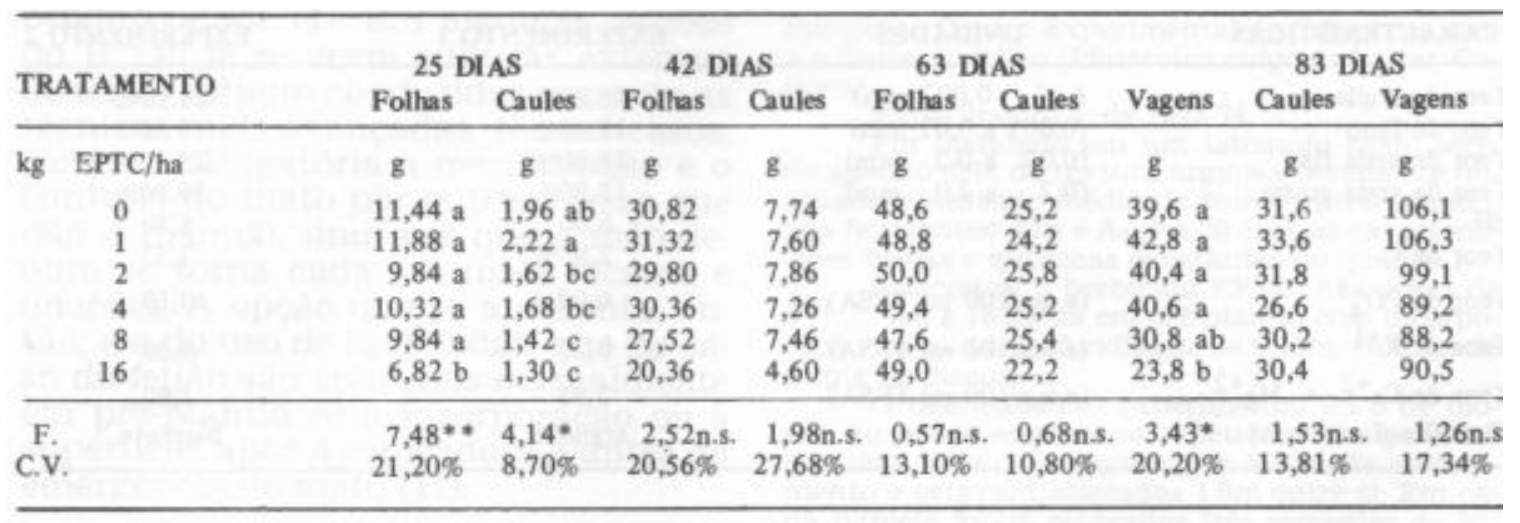

(*) - Significativo ao nível de $5 \%$

$(* *)$ - Significativo ao nível de $1 \%$

n.s. - Nầo significativo

obs.:- As médias, nas colunas, seguidas de letras comuns, não diferem entre si, ao nível de $5 \%$ pelo Teste de DUNCAN

Quadro 3 - Pesos de matéria seca de folhas, caules e vagens com sementes, por parcela, em cada época de amostragem do Experimento 2, em solo barrento. Médias de cinco repetições e amostras de dez plantas por parcela.

\begin{tabular}{|c|c|c|c|c|c|c|c|c|}
\hline \multirow{2}{*}{ TRATAMENTO } & \multicolumn{2}{|c|}{32 DIAS } & \multicolumn{2}{|c|}{45 DIAS } & \multirow[b]{2}{*}{ Folhas } & \multirow{2}{*}{$\begin{array}{l}70 \text { DIAS } \\
\text { Caules }\end{array}$} & \multirow[b]{2}{*}{ Vagens } & \multirow{2}{*}{$\begin{array}{l}87 \text { DIAS } \\
\text { Vagens }\end{array}$} \\
\hline & Folhas & Caules & Folhas & Caules & & & & \\
\hline $\mathrm{kg}$ EPTC/ha & $\mathrm{g}$ & $\mathrm{g}$ & g & g & g & 8 & g & $\mathrm{g}$ \\
\hline 0 & 14,2 & 3,26 & 41,32 & 16,56 a & $64,6 \mathrm{~b}$ & 44,0 & 136,0 & 179,4 \\
\hline 1 & 14,0 & 3,34 & 47,20 & 17,22 a & $68,8 \mathrm{ab}$ & 42,4 & 124,8 & 185,8 \\
\hline 2 & 13,2 & 3,16 & 43,14 & $15,64 \mathrm{a}$ & $74,0 \mathrm{ab}$ & 48,8 & 128,4 & 173,1 \\
\hline 4 & 14,2 & 3,30 & 47,22 & 15,24 a & $77,6 \mathrm{ab}$ & 46,2 & 129,8 & 189,4 \\
\hline 8 & 12,8 & 2,92 & 40,16 & $13,20 \mathrm{ab}$ & $82,2 \mathrm{ab}$ & 48,6 & 127,4 & 166,1 \\
\hline 16 & 9,2 & 2,30 & 33,30 & $10,12 \mathrm{~b}$ & 84,6 a & 46,0 & 99,4 & 162,3 \\
\hline F. & $\begin{array}{r}1,91 \\
23,95\end{array}$ & $\begin{array}{r}1,32 \\
25,18\end{array}$ & $\begin{array}{r}1,89 \\
20,10\end{array}$ & $\begin{array}{l}2,85^{*} \\
23.63\end{array}$ & $\begin{array}{r}2,88^{*} \\
13,49\end{array}$ & $\begin{array}{r}0,50 \\
17.19\end{array}$ & $\begin{array}{r}1,14 \\
21,47\end{array}$ & $\begin{array}{r}1,84 \\
12,41\end{array}$ \\
\hline C.V. $\%$ & 23,95 & 25,18 & 20,10 & 23,63 & 13,49 & 17,19 & 21,47 & 12,41 \\
\hline
\end{tabular}

(*) - Significativo ao nível de $5 \%$

Valores de $\mathrm{F}$, sem qualquer indicação, não foram significativos.

As médias, nas colunas, seguidas de letras comuns, não diferem entre si, ao nível de $5 \%$, pelo teste de Duncan.

atraso no ciclo. Na colheita, aos 83 dias, verificou-se boa recuperação das plantas. No Experimento 2, a redução de peso, causa da pela dose máxima, não foi tão pronunciada aos 70 ou 81 dias, mas confirma os resultados verificados no primeiro.

A ação fitotóxica do EPTC era esperada uma vez que as doses de 8 e 16 $\mathrm{kg} / \mathrm{ha}$ são bastante elevadas, duas equatro vezes maiores que a recomenda da para uso na cultura $(7,11)$.
Estes resultados concordam com o trabalho anteriormente conduzido nas mesmas condições de clima e solo argiloso, com doses de 17,28 e 21,60 $\mathrm{kg} / \mathrm{ha}$, com as variedades Chumbinhoopaco e Carioca (12). Nos dois experimentos, as condições de umidade e temperatura foram favoráveis a dissipação do EPTC no so- 
lo, uma vez que houve chuvas frequentes e temperaturas, em geral elevadas. Esses fatores aliados à dose aplicada são muito importantes em relação à persistência do EPTC no solo como o demonstraram diversos autores $(4,19$, 20). Os dois solos apresentaram teores relativamente baixos de M.O. O solo do Experimento 1 era mais argiloso mas apresentava-se mais úmido na aplicação que o solo do segundo. Mesmo es sas condições favoráveis a uma dissipação mais rápida do EPTC, não foram suficientes para evitar danos à cultura, nas doses de 8 e $16 \mathrm{~kg} / \mathrm{ha}$.

O feijoeiro é uma planta que apresenta elevada capacidade de degradar o EPTC, sendo partes da molécula incorporadas em diferentes compostos formados no seu metabolismo $(14,15)$. O EPTC é rapidamente metabolizado em feijão (4), quando aplicado em doses normais de uso agrícola. Sua mobilidade dentro da planta é também muito grande $(27,33)$. Mesmo assim verificouse que as doses de 8 e $16 \mathrm{~kg} / \mathrm{ha}$ de EPTC, aplicados ao solo, determinaram concentrações muito elevadas dentro da planta acima da capacidade de degradação. Esses teores elevados agiram na parte aérea, inibindo seu desenvolvi mento e causando os sintomas observados: folhas menores, bordos recurvados e pontos necrosados.

Nessas doses é possivel admitir a interferência do EPTC na fotossíntese,com inibição na fixação de $\mathrm{CO} 2$, o que já fora observado por Ashton (3).

A dose de $4 \mathrm{~kg} / \mathrm{ha}$, de uso corrente, não causou danos à cultura em qualquer é poca do ciclo, o que concorda com o resultado de vários trabalhos realizados com EPTC em nossas condi ções $(2,7,11,30)$.

O postulado de Arndt-Schulz afirma que qualquer veneno, em doses extremamente pequenas, atua como estimulantes nos processos fisiológicos. Nos experimentos aqui descritos, o EPTC, em doses sub-letais de 1 a $2 \mathrm{~kg} / \mathrm{ha}$, não apresentou qualquer efeito estimulante no crescimento das plantas.

Número de plantas e produção de grãos - Os resultados de números de plantas e produção de grãos do Experimento 1 estão no quadro 4 e os respecti vos resultados do Experimento 2, no quadro 5.

Em ambos os experimentos, partiuse de uma população inicial de 200.000 plantas por hectare ocorrendo redução média de $12,5 \%$ no primeiro e $26 \%$ no segundo até a colheita. Reduções do número de plantas durante o ciclo são normais e devido às causas diversas. No segundo experimento para as doses de 8 e $16 \mathrm{~kg} /$ ha parte de redução pode ser atribuida ao efeito fitotóxico severo no início do ciclo com morte de plantas já que a redução total foi da ordem de $35 \%$. Essa diferença foi significativa no caso do Experimento 2.

Quadro 4 - Número de plantas, produção de sementes, peso de matéria seca de vagens e peso de sementes mal formadas na cultura do Experimento 1, em solo argiloso. Médias de cinco repeti ções e amostragem de 18 metros lineares por parcela.

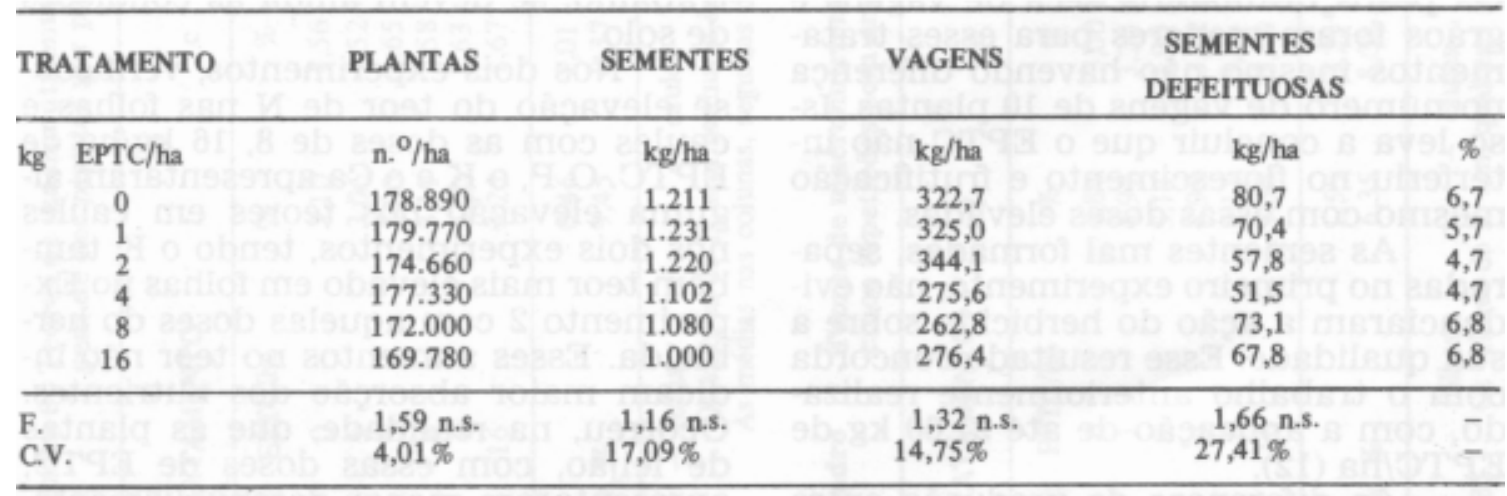

n.s. = não significativo 
Quadro 5 - Número de plantas, produção de sementes, peso de matéria seca e número de vagens na colheita do Experi mento 2, em solo barrento. Médias de cinco repetições e amostragem de dezoito metros lineares por parcela.

\begin{tabular}{|c|c|c|c|c|c|}
\hline \multicolumn{2}{|c|}{ TRATAMENTO } & \multirow{2}{*}{$\frac{\text { PLANTAS }}{n .0 / \mathrm{ha}}$} & \multirow{2}{*}{$\frac{\text { PRODUÇÁo }}{\mathrm{kg} / \mathrm{ha}}$} & \multicolumn{2}{|c|}{ VAGENS } \\
\hline kg & EPTC/ha & & & $\mathrm{kg} / \mathrm{ha}$ & n. $\% / 10$ plantas \\
\hline & 0 & 147.763 & $2033 \mathrm{a}$ & 488 & 148.2 \\
\hline & i & 144.199 & 2018 a & 465 & 139.8 \\
\hline & 2 & 139.319 & $2038 a$ & 475 & 1430 \\
\hline & 4 & 151.318 & $2067 \mathrm{a}$ & 558 & 163,4 \\
\hline & 8 & 130.431 & $1.649 \mathrm{~b}$ & 402 & 130.4 \\
\hline & 16 & 129.765 & $1.502 \mathrm{~b}$ & 409 & 130,2 \\
\hline \multirow{2}{*}{\multicolumn{2}{|c|}{$\begin{array}{l}\text { F. } \\
\text { C.V. }\end{array}$}} & $1,84 \mathrm{~ns}$. & $7,66^{*}$ & $1,03 \mathrm{~ns}$ & $1,13 \mathrm{~ns}$ \\
\hline & & 10.52 & 10,46 & 14,54 & 18,35 \\
\hline \multicolumn{6}{|c|}{$\begin{array}{l}\text { ns. - nfo significativo } \\
\text { (ब) - signifiativo so nivel de } 1 \%\end{array}$} \\
\hline \multicolumn{6}{|c|}{$\begin{array}{l}\text { Obs:- As medias, na colues de pro } \\
\text { tem entre ti, so nivel de } 5 \%\end{array}$} \\
\hline
\end{tabular}

A produção de grãos nos dois experimentos também apresentou valores menores nos tratamentos com as doses de 8 e $16 \mathrm{~kg} /$ ha de EPTC, sem ser significativa no primeiro. Pode-se afirmar que essas reduções foram devido aos tratamentos, pois os valores de produção acompanham os de peso de plantas desde o início do ciclo nos dois experimentos. As reduções de produção, nos dois experimentos, foram proporcionalmente maiores que as de número de plantas, portanto com menor produção por planta, para as doses mais elevadas, o que evidencia a ação fitotóxica do EPTC nesse caso. Parte dessa redução poderia ser atribuída ao atraso no ciclo da cultura. Todos os tratamentos foram colhidos no mesmo dia e aqueles com as doses de 8 e $16 \mathrm{~kg} / \mathrm{ha}$ não estavam ainda totalmente desenvolvidos. Os pesos de matéria seca de vagens e grãos foram menores para esses tratamentos mes mo não havendo diferença no número de vagens de 10 plantas. Is so leva a concluir que o EPTC não interferiu no florescimento e frutificação mesmo com essas doses elevadas.

As sementes mal formadas, separadas no primeiro experimento, não evidenciaram a ação do herbicida sobre a sua qualidade. Esse resultado concorda com o trabalho anteriormente realizado, com a aplicação de até $21,60 \mathrm{~kg}$ de EPTC/ha (12).

As diferenças de produção entre os dois experimentos devem ser atribuídas às condições do solo, já que as de clima foram muito favoráveis e seme - lhantes nos dois. o solo barrento do segundo ano apresentava melhores condições físicas e bom suprimento de fósfo ro, possibilitando melhor de senvolvi mento do sistema radicular. As plantas da cultura cresceram melhor nesse solo, durante todo ciclo (comparar quadros 2 e 3). A produção do Experimento 1, concorda com Almeida et al. (1) para a produção média de três anos para a região. Já no segundo experimento, a pro dução foi bem mais elevada, o que mostra a importância das condições de solo (quadros 4 e 5).

Teores de macronutrientes em caules e folhas - A análise química foi realizada no inicio do flor escimento, pois a porcentagem de nutrientes absorvida é muito grande até esse ponto (9, $17,21,25)$.

Por outro lado, o EPTC é um herbicida de curta persistência no solo, por ser altamente volátil (29) e sua ação so bre as plantas é muito pronunciada no início do seu ciclo, desaparecendo com o tempo.

Os teores de macronutrientes em caules e folhas no Experimento 1 estão no quadro 6 e os do Experimento 2, no quadro 7.

Os teores encontrados nos dois experimentos, de modo geral, concor dam com aqueles encontrados em outros trabalhos com a variedade Carioca $(8,13)$. Quando comparados com os teores de outras variedades, são, em geral, mais elevados $(9,17,21,25)$, resultados devidos às características das varieda des. Além disso, as variações nos teores, mesmo nos dois experimentos deste trabalho, se devem ainda às condições de solo.

Nos dois experimentos, verificou se elevação do teor de $\mathrm{N}$ nas folhas $\mathrm{e}$ caules com as doses de $8,16 \mathrm{~kg} / \mathrm{ha}$ de EPTC. O P, o $\mathrm{K}$ e o $\mathrm{Ca}$ apresentaram alguma elevação nos teores em caules nos do is experimentos, tendo o $\mathrm{K}$ tam bém teor mais elevado em folhas no Experimento 2 com aquelas doses do herbicida. Esses aumentos no teor não indicam maior absorção dos nutrientes. Ocorreu, na realidade, que as plantas de feijão, com essas doses de EPTC, apresentaram menor desenvolvimento, portanto, menor produção de matéria 
Quadro 6 - Teores de macronutrientes em folhas e caules de feijáo, aos 45 dias após semeadura, no Experimento 2, em solo barrento. Amostragem de dez plantas por parcela em cinco repetiçōes.

\begin{tabular}{|c|c|c|c|c|c|c|c|c|c|c|c|c|c|}
\hline \multirow{2}{*}{\multicolumn{2}{|c|}{ TRATAMENTO }} & \multicolumn{2}{|c|}{$\mathbf{N}$} & \multicolumn{2}{|c|}{$\mathbf{P}$} & \multicolumn{2}{|c|}{$\mathbf{K}$} & \multicolumn{2}{|c|}{$\mathrm{Ca}$} & \multicolumn{2}{|c|}{$\mathbf{M g}$} & \multicolumn{2}{|c|}{$\mathbf{S}$} \\
\hline & & f & c & f & c & $\mathbf{f}$ & c & $\mathbf{f}$ & c & f & c & f & c \\
\hline \multirow[t]{7}{*}{ kg } & EPTC/ha & $\%$ & $\%$ & $\%$ & $\%$ & $\%$ & $\%$ & $\%$ & $\%$ & $\%$ & $\%$ & $\%$ & $\%$ \\
\hline & 0 & 3,10 & 1,56 & 0,371 a & 0,263 & 2,57 & 2,58 & 2,24 & 0,87 & 0,55 & $0,37 a b$ & 0,249 & 0,345 \\
\hline & 1 & 3,06 & 1,52 & $0,372 \mathrm{ab}$ & 0,249 & 2,60 & 2,58 & 2,40 & 0,87 & 0,58 & $0,37 \mathrm{ab}$ & 0,281 & 0,363 \\
\hline & 2 & 3,00 & 1,65 & 0,366 a & 0,268 & 2,63 & 2,79 & 2,23 & 0,86 & 0,54 & 0,35 b & 0,270 & 0,365 \\
\hline & 4 & 3,11 & 1,58 & $0,328 \mathrm{~b}$ & 0,271 & 2,38 & 2,64 & 2,19 & 0,97 & 0,55 & $0,42 \mathrm{a}$ & 0,253 & 0,342 \\
\hline & 8 & 3,20 & 1,63 & $0,332 \mathrm{~b}$ & 0,266 & 2,54 & 2,82 & 2,10 & 0,95 & 0,53 & $0,39 \mathrm{ab}$ & 0,267 & 0,357 \\
\hline & 16 & 3,25 & 1,67 & 0,370 a & 0,291 & 2,81 & 3,01 & 2,26 & 0,99 & 0,57 & 0,41 a & 0,302 & 0,393 \\
\hline \multirow{2}{*}{\multicolumn{2}{|c|}{$\begin{array}{l}\text { F. } \\
\text { c.V. \% }\end{array}$}} & 0,46 & 1,01 & $3,95^{*}$ & 1,38 & 0,84 & 1,16 & 0,79 & 2,65 & 0,29 & $3,30^{*}$ & 1,34 & 1,58 \\
\hline & & 9,45 & 8,37 & 6,26 & 8,40 & 13,06 & 12,81 & 11,14 & 8,39 & 14,09 & 8,44 & 13,88 & 8,98 \\
\hline
\end{tabular}

f - folhas

c - caules

(*) - significativo ao nível de $5 \%$

Os valores de $\mathrm{F}$, sem nenhuma indicaçâo, não foram significativos.

As médias nas colunas, seguidas de letras comuns, não diferem entre si, ao nível de $5 \%$, pelo teste de Duncan.

Quadro 7-Teores de macronutrientes em folhas e caules de feijáo, aos 45 dias após semeadura, no Experimento 1,em solo argiloso. Médias de cinco repetiçóes com amostragem de dez plantas por parcela.

\begin{tabular}{|c|c|c|c|c|c|c|c|c|c|c|c|c|c|}
\hline \multirow{2}{*}{\multicolumn{2}{|c|}{ TRATAMENTO }} & \multicolumn{2}{|c|}{$\mathbf{N}$} & \multicolumn{2}{|c|}{$\mathbf{P}$} & \multicolumn{2}{|c|}{$\mathbf{K}$} & \multicolumn{2}{|c|}{$\mathrm{Ca}$} & \multicolumn{2}{|c|}{$\mathrm{Mg}$} & \multicolumn{2}{|l|}{$\mathbf{S}$} \\
\hline & & f & c & $\mathbf{f}$ & c & f & c & f & c & f & c & f & c \\
\hline \multirow[t]{7}{*}{$\mathrm{kg}$} & EPTC/ha & $\%$ & $\%$ & $\%$ & $\%$ & $\%$ & $\%$ & $\%$ & $\%$ & $\%$ & $\%$ & $\%$ & $\%$ \\
\hline & 0 & 4,84 & $3,00 \mathrm{a}$ & 0,497 & 0,358 & 3,62 & $4,35 \mathrm{a}$ & 2,56 & 1,27 & 0,64 & 0,36 & $0,519 \mathrm{a}$ & $0,450 \mathrm{ab}$ \\
\hline & 1 & 4,97 & $3,20 \mathrm{ab}$ & 0,472 & 0,351 & 3,69 & $4,26 \mathrm{a}$ & 2,52 & 1,26 & 0,65 & 0,37 & $0,501 \mathrm{ab}$ & $0,474 \mathrm{ab}$ \\
\hline & 2 & 5,11 & $2,90 \mathrm{a}$ & 0,491 & 0,349 & 3,26 & 4,55 a & 2,55 & 1,30 & 0,63 & 0,36 & $0,482 \mathrm{ab}$ & 0,479 a \\
\hline & 4 & 4,99 & $3,12 \mathrm{ab}$ & 0,469 & 0,391 & 3,57 & 4,46 a & 2,52 & 1,31 & 0,62 & 0,36 & $0,466 \mathrm{abc}$ & $0,447 \mathrm{bc}$ \\
\hline & 8 & 5,11 & $3,36 \mathrm{~b}$ & 0,480 & 0,379 & 3,47 & $4,73 \mathrm{ab}$ & 2,61 & 1,36 & 0,65 & 0,38 & $0,397 \mathrm{c}$ & $0,429 b c$ \\
\hline & 16 & 5,36 & $3,44 \mathrm{~b}$ & 0,477 & 0,377 & 3,61 & $4,97 \mathrm{~b}$ & 2,44 & 1,38 & 0,62 & 0,37 & $0,445 \mathrm{bc}$ & $0,422 \mathrm{c}$ \\
\hline \multirow{2}{*}{\multicolumn{2}{|c|}{$\begin{array}{l}\text { F. } \\
\text { c.V. \% }\end{array}$}} & 1,55 & $3,29^{*}$ & 0,46 & 0,92 & 1,11 & $3,04^{*}$ & 0,92 & 0,64 & 0,63 & 0,33 & $3,58^{*}$ & $5,06^{* * *}$ \\
\hline & & 6,35 & 8,08 & 7,47 & 10,96 & 9,25 & 7,39 & 4,92 & 10,40 & 6,92 & 8,33 & 10,95 & 5,08 \\
\hline
\end{tabular}

f - folhas c - caules (*) - significativo ao nível de $5 \%$

(**) - significativo ao nivel de $1 \%$

OBS.: Os valores de F, sem qualquer indicação, não foram significativos. As médias, nas colunas, seguidas de letras comuns, não diferem entre si, ao nível de $5 \%$, pelo teste de Duncan. 
seca. A extração desses nutrientes pelo feijão com essas doses foi sempre menor do que nos tratamentos com $0,1,2$ ou 4 $\mathrm{kg} / \mathrm{ha}$ de EPTC, nos dois experimentos. Nestes tratamentos, não se verificou qualquer variação em teor ou extração. Os resultados mostram que mesmo com o crescimento prejudicado, as plantas não apresentaram grandes variações na absorção de nutrientes.

Em trabalho anterior, com aplicação de EPTC, nas doses de 4,32 e 5,76 kg/ ha, à altura de feijão em solo argiloso, também não se verificou qualquer alteração nos teores de N, P, K, Ca e Mg em folhas ou caules, aos 32 dias, concordando, portanto, com os resultados aqui descritos para a aplicação de $4 \mathrm{~kg} /$ ha, nos dois experimentos (13).

O teor de enxofre foi significativamente menor nos tratamentos com as doses mais elevadas de EPTC, no Experimento 1 , contrariando o que ocorreu com os demais nutrientes. No Experi mento em solo barrento, não ocorreu o mesmo. Também houve diferença em relação ao local de maior concentração de enxofre nas plantas, sendo o teor mais elevado nos caules no Experimen to 2 e maior nas folhas no primeiro.

Os resultados diferentes dos dois experimentos devem ser atribuidos a diferenças de disponibilidade do $\mathrm{S}$ nos dois solos. Não foram analisados os teo res de $\mathrm{S}$ nos solos, uma vez que não é prática normal essa determinação.

Teores de macronutrientes em vagens e sementes - Os teores de macronutrientes em vagens e sementes do Experimento 1 estão no quadro 8, e os respectivos teores do Experimento 2, no quadro 9.

Comparando-se os resultados dos dois experimentos, verificou-se que os teores dos nutrientes nas vagens são sempre mais elevados no primeiro, com excessão para o $\mathrm{N}$ e $\mathrm{S}$ quando foram iguais. No caso das sementes o mesmo ocorreu para $\mathrm{N}$ e $\mathrm{K}$. O P, o Ca e o $\mathrm{Mg}$ apresentaram teores iguais e o $\mathrm{S}$ mais elevado no segundo.

O teor de $\mathrm{N}$, significativamente mais elevado em vagens, sem aplicação de EPTC, parece ter sido casual no Experimento 2 .

$\mathrm{O}$ teor de $\mathrm{K}$ nas vagens foi significativamente mais elevado, com aplica ção de 8 e $16 \mathrm{~kg} /$ ha de EPTC, no Experi-

mento 1 e com a dose mais elevada no
Experimento 2. Houve, também elevação no teor de $\mathrm{S}$ em vagens com as doses de 1, 4, 8 e $16 \mathrm{~kg} /$ ha do herbicida, no segundo Experimento.

O potássio é um nutriente muito móvel nas plantas e se transloca, de modo geral, totalmente para os frutos. No caso dos experimentos aqui relata dos não se pode afirmar que houve uma ação direta do EPTC sobre o movimento desse nutriente no feijão. Parece que o ocorrido é apenas uma decorrência da maior concentração do $\mathrm{K}$ nos caules, como foi visto nas análises dessas partes da planta. O atraso no ciclo da cul tura pode ter causado absorção por mais tempo que o normal. De qualquer forma, não houve elevação no teor de $\mathrm{K}$ nas sementes, in dicando que o exce dente não é transferido para elas.

Para o caso do S, o fato de ocorrerem teores mais elevados em apenas um dos experimentos, e justamente naquele em que os teores em caules e folhas eram bem menores, dificulta a explicação. Pode-se admitir que houve absorção desse nutriente por período mais longo que o normal, talvez devido ao atraso do ciclo da cultura, como ocorreu com o K.

Segundo Haag et al. (21) todo S exigido pelo feijoeiro é absorvido até os 60 dias, sendo 98,6\% do total absorvido até os 50 dias. O S absorvido mais tardiamente teria se acumulado nas va gens diretamente, uma vez que é pouco móvel dentro das plantas.

Considerando a marcha de absorção dos macronutrientes pelo feijoeiro, todo o $\mathrm{N}$ e o $\mathrm{K}$ necessários à planta são absorvidos até os 50 dias do ciclo. São justamente esses dois nutrientes os requeridos em maior quantidade pelo feijoeiro, indicando isso que é muito grande a quantidade absorvida na metade inicial do ciclo.

$\mathrm{O}$ que foi verificado é que o EPTC, mesmo em doses de 8 e $16 \mathrm{~kg} / \mathrm{ha}$, que reduziram o crescimento das plantas não impediu a absorção de $\mathrm{N}$ e K. Nessas doses eles foram absorvidos em quantidade acima da proporção normal. Isso é devido ao efeito de diluição. Em plantas com desenvolvimento normal, os teores dos nutrientes variam dentro de certos limites. Se o crescimento é acelerado, com maior produção de massa seca, os 
Quadro 8 - Teores de macronutrientes em vagens e sementes de feijáo, na colheita do Experimento 1, em solo argiloso. Médias de cinco repetiçóes com amostragem de dez plantas por parcela.

\begin{tabular}{|c|c|c|c|c|c|c|c|c|c|c|c|c|}
\hline \multirow[b]{2}{*}{ TRATAMENTO } & \multicolumn{2}{|c|}{$\mathbf{N}$} & \multicolumn{2}{|c|}{$\mathbf{P}$} & \multicolumn{2}{|c|}{$\mathbf{K}$} & \multicolumn{2}{|c|}{$\mathrm{Ca}$} & \multicolumn{2}{|c|}{$\mathbf{M g}$} & \multicolumn{2}{|c|}{$\mathbf{S}$} \\
\hline & V & $\mathbf{S}$ & V & $\mathbf{S}$ & $\mathbf{V}$ & $\mathbf{S}$ & $\mathbf{V}$ & $\mathbf{S}$ & $\mathbf{v}$ & $\mathbf{S}$ & $\mathbf{V}$ & $\mathbf{S}$ \\
\hline kg EPTC/ha & $\%$ & $\%$ & $\%$ & $\%$ & $\%$ & $\%$ & $\%$ & $\%$ & $\%$ & $\%$ & $\%$ & $\%$ \\
\hline 0 & 0,75 & 3,48 & 0,060 & 0,388 & 2,08 a & 1,50 & 0,77 & 0,19 & 0,33 & 0,20 & 0,130 & 0,163 \\
\hline 1 & 0,89 & 3,63 & 0,053 & 0,364 & 2,08 a & 1,46 & 0,78 & 0,18 & 0,34 & 0,19 & 0,129 & 0,170 \\
\hline 2 & 0,74 & 3,60 & 0,052 & 0,358 & 2,06 . a & 1,49 & 0,79 & 0,19 & 0,33 & 0,20 & 0,119 & 0,153 \\
\hline 4 & 0,71 & 3,65 & 0,053 & 0,365 & $2,09 \mathrm{a}$ & 1,43 & 0,77 & 0,17 & 0,33 & 0,19 & 0,127 & 0,178 \\
\hline 8 & 0,59 & 3,53 & 0,053 & 0,384 & $2,42 \mathrm{~b}$ & 1,44 & 0,74 & 0,19 & 0,32 & 0,19 & 0,132 & 0,148 \\
\hline 16 & 0,75 & 3,68 & 0,064 & 0,358 & $2,62 \mathrm{~b}$ & 1,43 & 0,75 & 0,19 & 0,35 & 0,20 & 0,123 & 0,138 \\
\hline F. & 1,23 & 1,49 & 1,95 & 2,20 & $4,69^{*}$ & 1,12 & 0,45 & 0,15 & 0,60 & 0,67 & 0,88 & 1,42 \\
\hline C.V. \% & 26,27 & 3,75 & 14,14 & 5,41 & 10,99 & 4,40 & 8,65 & 19,06 & 6,68 & 4,87 & 9,52 & 17,62 \\
\hline
\end{tabular}

$\mathrm{V}$ - vagens $\quad \mathrm{S}$ - sementes

Os valores de $\mathrm{F}$. sem nenhuma indicação não foram significativos

OBS: As médias, na coluna de K, seguidas de letras iguais, não diferem entre si, ao nível de 5\%, pelo teste de Duncan. 
Quadro 9 - Teores de macronutrientes em vagens e sementes de feijâo, na colheita do Experimento 2, em solo barrento. Amostragem de dez plantas por parcela em cinco repetiçóes.

\begin{tabular}{|c|c|c|c|c|c|c|c|c|c|c|c|c|c|}
\hline \multirow{2}{*}{\multicolumn{2}{|c|}{ TRATAMENTO }} & \multicolumn{2}{|c|}{$\mathbf{N}$} & \multicolumn{2}{|c|}{$\mathbf{P}$} & \multicolumn{2}{|c|}{$\mathbf{K}$} & \multicolumn{2}{|c|}{$\mathrm{Ca}$} & \multicolumn{2}{|c|}{ Mg } & \multicolumn{2}{|l|}{$\mathbf{S}$} \\
\hline & & $\mathbf{V}$ & $\mathbf{S}$ & $\mathbf{V}$ & $\mathbf{S}$ & $\mathbf{V}$ & $\mathbf{S}$ & $\mathbf{v}$ & $\mathbf{S}$ & $\mathbf{v}$ & $\mathbf{s}$ & $\mathbf{v}$ & $\mathbf{s}$ \\
\hline \multirow[t]{7}{*}{$\mathrm{kg}$} & EPTC/ha & $\%$ & $\%$ & $\%$ & $\%$ & $\%$ & $\%$ & $\%$ & $\%$ & $\%$ & $\%$ & $\%$ & $\%$ \\
\hline & 0 & $1,00 \mathrm{a}$ & 3,10 & 0,048 & 0,375 & $1,45 \mathrm{~b}$ & 1,37 & 0,61 & 0,19 & 0,30 & 0,18 & $0,117 \mathrm{c}$ & 0,248 \\
\hline & 1 & $0,76 \mathrm{~cd}$ & 2,66 & 0,044 & 0,339 & $1,44 \mathrm{~b}$ & 1,30 & 0,55 & 0,16 & 0,29 & 0,18 & $0,129 a b c$ & 0,247 \\
\hline & 2 & $0,68 \mathrm{~d}$ & 2,86 & 0,041 & 0,360 & 1,77 a & 1,39 & 0,52 & 0,17 & 0,29 & 0,19 & $0,120 \mathrm{bc}$ & 0,229 \\
\hline & 4 & $0,73 \mathrm{~cd}$ & 2,66 & 0,046 & 0,366 & $1,42 \mathrm{~b}$ & 1,37 & 0,60 & 0,19 & 0,31 & 0,19 & $0,146 \mathrm{ab}$ & 0,247 \\
\hline & 8 & 0,85 bc & 2,92 & 0,048 & 0,380 & $1,41 \mathrm{~b}$ & 1,35 & 0,52 & 0,18 & 0,28 & 0,18 & $0,150 \mathrm{ab}$ & 0,232 \\
\hline & 16 & $0,94 \mathrm{abc}$ & 2,90 & 0,057 & 0,392 & 1,85 a & 1,40 & 0,56 & 0,19 & 0,32 & 0,19 & 0,151 a & 0,255 \\
\hline \multirow{2}{*}{\multicolumn{2}{|c|}{$\begin{array}{l}\text { F } \\
\text { C.V. \% }\end{array}$}} & $4,54^{*}$ & 1,19 & 1,06 & 1,11 & $3,56^{*}$ & 2,24 & 1,57 & 0,77 & 1,34 & 2,00 & $2,71^{*}$ & 1,13 \\
\hline & & 19,52 & 12,08 & 24,46 & 10,58 & 15,03 & 4,03 & 12,33 & 15,36 & 10,64 & 5,35 & 15,73 & 8,69 \\
\hline
\end{tabular}

\section{V - vagens $\mathrm{S}$ - sementes}

(*) - significativo ao nível de $5 \%$. Os valores de $\mathrm{F}$, sem nenhuma indicaça não foram significativos. As médias nas mesmas colunas, seguidas de letras comuns, não diferem entre si ao nível de $5 \%$, pelo teste de Duncan. 
teores serão menores, proporcionalmente, e se for restringido, com menor produção de massa seca, os teores poderão ser proporcionalmente maiores. Assim, parece que o EPTC não agiu diretamen te sobre o mecanismo de absorção de $\mathrm{N}$ e K. Os teores desses nutrientes foram mais elevados, mas a extração do solo foi menor nesses tratamentos. Para o caso de $\mathrm{S}$, houve redução dos teores em folhas e caules no Experimento 1, mas sem alteração no segundo. Para os demais nutrientes, que são requeridos em quantidades bem menores do que $\mathrm{N}$ e $\mathrm{K}$, só houve redução da extração, com aplicação da dose máxima do EPTC.

Comparando os teores de macronutrientes, nas sementes, da variedade Carioca, encontrados nos dois experimentos, com aquelas das variedades Chumbinho-opaco, Pintado e Rico 23, verifica-se que não houve diferenças marcantes $(9,17,21,25)$.

$O$ herbicida EPTC, em qualquer das doses aplicadas, não afetou o teor de nenhum dos macronutrientes nas sementes. A quantidade abs orvida de qualquer deles por planta foi sempre menor com as doses de 8 e $16 \mathrm{~kg} / \mathrm{ha}$ do herbicida, em função do menor desenvolvimento das plantas.

Nas vagens ocorreu o mesmo no primeiro experimento, com exceção de K. No Experimento 2, mesmo com as duas doses mais elevadas do EPTC, quase não ocorreu redução da quantidade de nutrientes absorvidos por planta, sendo, também, o $\mathrm{K}$ mais absorvido nesse caso, com a dose maior.

Não foi verificada proporcional mente entre os teores de $\mathrm{N}$ e S. Havia mais enxofre nas sementes, no Experimento 2, do que no primeiro, sendo o teor de $\mathrm{N}$ um pouco inferior naquele. Neste caso, o S poderia ter entrado como constituinte de outros compostos que não a proteína, ou se formaram mais aminoácidos sulfurados compondo-se uma reserva proteica diferente.

\section{LITERATURA CITADA}

1. Almeida, L.D'A; Leitáo F. ․ H.F. \& Miyasaka, S. Feijoeiro no Estado de Sáo Paulo. Campinas, Instituto Agronómico, 1971. 8p. (Circular 7).

2. Alves, A. \& Bernardi, J.B. Controle de ervas daninhas em feijâo vagem pelo uso de herbici- das. In: Sem. Bras. de Herbicidas e Ervas Daninhas, 6, Sete Lagoas, 1966. Anais p. 257-262.

3. Ashton, F.M. Effect of EPTC on photosynthesis, respiration and oxidative phosphorylation. Weeds 11: 295-297, 1963.

4. Ashton, F.M. \& Sheets, T.J. The relationship of soil adsorption of EPTC to oats injury in various soil types, Weeds 7: 88-90, 1969 .

5. Bataglia, O.C. A determinaçâo indireta do enxofre em plantas por espectrofotometria de absorçảo atômica. Ciência e Cultura 28: 672 $675,1976$.

6. Bataglia, O.C. \& Gallo, J.R. A determinação de cálcio e magnésio em plantas por fotometria de chama de absorçâo. Bragantia 31: 5774, 1972 .

7. Brasil. Departamento Nacional de Pesquisa Agropecuária. Controle químico das plantas invasoras. Cultura do feijâo. Brasilia, Comissáo Nacional de Herbicidas e Ervas Daninhas, 1973. 3p. (Indicaçáo da Pesquisa 5).

8. Bulisani, E.A.; Almeida. L.D'A de \& Demattê, J. Observaçōes preliminares sobre a adubaçāo foliar em feijoeiro (Phaseolus vulgaris L.), Bragantia 32: XIII-XVII, 1973. (Nota 3).

9. Cobra Neto, A.; Accorsi, W.R. \& Malavolta, E. Estudos sobre a nutriçáo mineral do feijoeiro (Phaseolus vulgaris L. var. Roxinho). Anais da E.S.A. Luiz de Queiroz* 28: 257-274, 1971.

10. Danielson, L.L.; Gentner, N.A. \& Jansen, L.L. Persistence of soil-incorporates EPTC and other carbamates. Weeds 9: 463-476, 1961.

11. Deuber, R. \& Forster, R. Ensaios de herbicidas em culturas de feijâo. Campinas, Instituto Agronômico, 1974a. 28p. (Boletim técníco 13),

12. Deuber, R. \& Forster, R. Controle de tiririca (Cyperus rotundus L.) com aplicaçóes sucessivas de EPTC, em cultura de feijāo. Bragantia 33: $97-108,1974 b$.

13. Deuber, R. \& Hiroce, R. Influência de herbicidas na concentraçáo de macronutrientes em plantas de milho e feijāo. Bragantia 33: CXVCXXI, 1974. (Nota 23)

14. Fang, S.C. Thiolcarbamates. In: Kearney, P.C. \& Kaufman, D.D., eds. Degradation of herbicides. New York, Marcel Dekker, 1969. p.147-164.

15. Fang, S.C. \& George, M. Metabolism of propyl1-C' - (N.N - ethyl,n - butil) - thiocarbamate in plants. Plant Physiol. Suppl. 37. XXVI, 1962.

16. Forster, R. \& Alves, A. Observaçōes sobre a aplicaçâo do Eptam no combate ás ervas más na cultura do feijoeiro. In: Sem. Bras. de Herbicidas e Ervas Daninhas, 3. Campinas, 1960. Anais, p.267-282.

17. Gallo, J.R. \& Miyasaka, S. Composição quimica do feijoeiro e absorçáo de elementos nutritivos, do florescimento à maturação. Bragantia 20: 867-884, 1961.

18. Gill, H.S. Some effects of triazine, amino-triazole, 2,4-D and EPTC on growth, transpiration and mineral absorption in Cyperus esculentus, Triticum sp. and Zea mays: Thesis Ph.D., Ohio State Univ., 1968. 90p. In: Weed Abstracts 18: 2402, 1969.

19. Gray, R.A. A vapor trapping apparatus for determining the loss of EPTC and other herbicides from soils. Weeds 13: 138-141, 1965. 
20. Gray, R.A. \& Weierich, A.J. Factors affecting the vapor loss of EPTC from soils. Weeds 13: 141-147, 1965.

21. Haag, H.P.; Malavolta, E.; Gargantini, H. \& Blanco, H.G. Absorção de nutrientes pela cultura do feijoeiro. Brag antia 26: 381-391, 1967.

22. Jordan, L.S. \& Day, B.E. Effects of soil properties on EPTC phytotoxicity. Weeds 10: 212$215,1962$.

23. Kirgisbaev, A. \& Nasyrova, T.K. (The effect of herbicides on some nitrogeneous compounds of cotton at different soil moisture contents). Uzbek. biol. Zh 13: 26-29, 1969. In: Weed Abstracts 20: n. ${ }^{\circ} 873,1971$.

24. Lott, W.L.; Nery, J.P.; Gallo, J.R. \& Medcalf, J.C. A técnica de análise foliar aplicada ao cafeeiro. Campinas, Instituto Agronómico, 1956. 29p. (Boletim 79).

25. Mafra, R.C. Absorçáo e distribuiçăo de nutrientes minerais no feijoeiro (Phaseolus vulgaris L.): Efeitos da densidade e da época de plantio: Dissertaçăo. Viçosa, U.F.V., 1972. 86p.

26. Melfi, A.J.; Girardi, A.V. \& Moniz, A.C. Mineralogia dos solos da Estaçáo Experimental "Theodureto de Camargo" em Campinas. Bragantia 25: 9-30, 1966.
27. Nalewaja, J.D.; Behrens, R. \& Schmid, A.R. Uptake translocation and fate of $\mathrm{C}^{4}$-EPTC in alfalfa. Weeds 12: 269-272, 1964.

28. Perkin-Elmer. Analytical methods for atomic absorption spectro-photometry. Norwalk, Connecticut, 1971.

29. Thomson, W.T. Agricultural chemicals. II. Herbicides Fresno, California. Thomson Publications, $1973.300 \mathrm{p}$.

30 . Victoria $\mathbf{F},{ }^{\circ}, \mathbf{R}$. Herbicidas na cultura do feijáo (Phaseolus vulgaris L.): controle, fitotoxicidade e persistência no solo: Dissertaçăo. Piracicaba, U.S.P., 1975. 102p.

31. Wiedmann, S.J. \& Appleby, A.P. Plant growth stimulation by sublethal concentrations of herbicides. Weeds Res. 12: 65-74, 1972.

32. Wilkinson, R.E. \& Hardcastle, W.S. EPTC effects on total leaflet fatty acids hydrocarbons. Weeds Sei. 18: 125-128, 1970.

33. Yamagushi, S. Absorption and distribution of ${ }^{3 S}$ S-EPTC. Weeds 9: 374-380, 1961.

34. Zagatto, E.A.G. Utilizaçāo da análise por ativaçâo neutrônica náo destrutiva para determinaçāo de alguns elementos em folhas de feijoeiros (Phaseolus vulgaris L.) tratados com herbicidas: Dissertaçảo. Piracicaba, USP, 1974. $79 \mathrm{p}$. 